\title{
Pilot Study: Effectiveness of Complex Decongestive Therapy (CDT) for lymphedema in palliative care patients with advanced cancer
}

Background: CDT is a regime of physical treatments for lymphoedema. Its effectiveness is unknown in advanced cancer patients. This study evaluates effectiveness of CDT in this population.

\section{Method:}

Prospective observational cohort study over 18 months of advanced cancer patients with lymphoedema, who received 3 or more CDT interventions. Measurements were taken before the first (T1), third (T3) and sixth (T6) treatments as follows: Limb volume using circumferential measurements, quality of life (QOL) using qualitative questions, skin quality using a locallydeveloped scale measuring colour, thickness and texture. The treating physiotherapists collected data. Analysis used Microsoft Excel and SPSS.

Results: 12 patients, age range 42-73 (median 69.5) were included. Survival from last recorded treatment ranged from 3-262 days (median 40).

At T3 ( $n=21$ limbs) volume reduction was significant [Wilcoxin Signed Rank Test $Z=-2.5, p=0.01$, $r=0.5]$. At $T 6(n=13$ limbs) volume reduction was significant $[Z=-2.4, p=0.013, r=0.66]$. At both time points, there were significant reductions in abnormal skin thickness and surface, but not colour. Improvements occurred independent of volume changes. QOL changes included better function, improved limb aesthetics, and less pain and tightness.

Conclusion: For the first time, this study shows that CDT is effective for a cohort of palliative cancer patients with limited survival. Improvements in limb volume, skin quality and lymphoedema-related QOL were recorded. Valid skin and QOL measures need to be developed. Larger, blinded trials need to be conducted to determine which patients benefit from CDT.

\section{Introduction}

Lymphedema commonly occurs in palliative care (PC) patients with advanced cancer [1]. Causes include blockage by tumours, node removal, radiation and hypoalbuminaemia [2]. In this population, lymphedema affects function, body image, interpersonal relationships and causes anxiety about the future [3]. Lymphoedema may increase the risk of deep venous thrombosis [4] and skin abnormalities include dryness, increased thickness, hyperkeratosis, lymphorrhea, risk of cellulitis $[5,6]$.

Management is based on complex decongestive therapy (CDT) [2], which has proven effectiveness in cancer populations without advanced disease [7]. CDT comprises skincare, exercise, compression (bandaging and/or garments) and lymphatic massage. In PC patients, reported benefits include volume reduction, improved function, improved skin integrity $[5,8,9,10]$, but effectiveness remains unproven. 
The only systematic review found on lymphedema in PC patients [11] reported limited evidence to support CDT, based on 3 mixed-population studies. Our search revealed just one retrospective study specifically researching CDT in PC patients [12], which reported effectiveness in reducing pain and dyspnoea.

In PC patients, volume reduction is not always realistic. Goals of CDT may include maintenance/ improvement in quality of life (QOL) or skin integrity [13]. Our pilot study, the first known, aims to measure effectiveness of CDT on limb volume, skin quality and QOL in advanced cancer patients with lymphedema.

\section{Methodology:}

Prospective longitudinal pilot over 18 months (August 2013 - Jan 2015) in Milford Care Centre, Limerick, Ireland. This is a specialist PC service comprising both inpatient and day units, as well as a hospice-at-home service. The edema service is provided by PC physiotherapists, trained as lymphedema therapists. Management is physiotherapy-led, in consultation with medical staff as required. Ethical approval granted by the Ethics Committee of University Hospital Limerick in June 2013.

\section{Population:}

PC patients referred to the edema service. Recruitment was conducted by the treating physiotherapists. Inclusion and Exclusion criteria outlined in Table 1.

Table 1: Inclusion and Exclusion Criteria

\begin{tabular}{|c|c|}
\hline Inclusion & Exclusion \\
\hline $\begin{array}{l}\text { - advanced cancer patients with } \\
\text { lymphedema of arms or legs } \\
\text { - likely to tolerate treatment burden } \\
\text { (assessed by physiotherapist) } \\
\text { - had } 3 \text { or more treatments for } \\
\text { lymphedema. } \\
\text { - } \quad \text { signed consent }\end{array}$ & $\begin{array}{l}\text { - } \\
\text { - } \text { matients with non-lymphatic edema or } \\
\text { treatments } \\
\text { - } \quad \text { CDT had commenced prior to study } \\
\text { - had confounding treatments that might } \\
\text { reduce edema (radiotherapy, diuretics, } \\
\text { organ failure which was reversed } \\
\text { medically) } \\
\text { - had contraindications for CDT (recent } \\
\text { DVT, cellulitis, total blockage by } \\
\text { tumour). }\end{array}$ \\
\hline
\end{tabular}

\section{Intervention:}

Individually-tailored programme, using a range of the following: bandaging, lymphatic massage, compression garments, kinesiotaping, exercise, deep breathing techniques, education and skincare. 


\section{Outcomes Measures:}

Measurements were recorded by the treating physiotherapist before the initial treatment (T1), before the third (T3) and sixth (T6) treatments.

1) Limb volume.

The gold standard is circumferential measurement of limbs [14, 15]. Measurement points were as follows:

Arm: knuckles, styloid process, elbow crease, $10 \mathrm{~cm}$ above elbow.

Leg: base of $5^{\text {th }}$ metatarsal, around malleoli, widest point of calf, tibial tuberosity, $10 \mathrm{~cm}$ above tuberosity, $20 \mathrm{~cm}$ above tuberosity.

Volume was calculated using truncated cone measurements [16]:

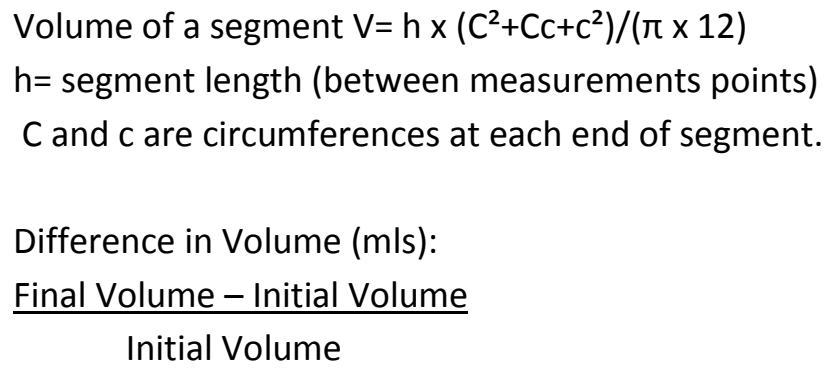

2) Skin changes

Our lymphedema team clinically reports skin changes post-CDT in 3 domains: colour, thickness and surface. A suitable clinical tool was not found, therefore one was developed to measure abnormalities in these domains (Appendix 1). Reliability and validity studies have yet to be conducted. Inter-rater reliability was not a factor.

\section{3) QOL changes}

LYMQOL [17] was chosen, the shorter of two lymphedema-specific QOL tools available. However, the first 3 patients required assistance to complete, thereby rendering results invalid. Thereafter, two qualitative questions were asked of subsequent patients at T3 $(n=9)$ and T6 $(n=5)$.

\section{'Have you noticed any changes since receiving the lymphedema treatment?'}

'If so, what changes have you noticed?'

Data Analysis:

Results were filled out by the treating physiotherapist on paper, and transferred to a passwordsecured Microsoft Excel sheet. Statistical analysis used Excel and SPSS. Qualitative information was analysed using thematic analysis [18]. 


\section{Results}

In 18 months, there were 141 new referrals to the edema service, 17 agreed to participate in the study, 12 were included for analysis following attrition (Figure 1). All had advanced cancer, median survival 40 days from final treatment (Table 2). At T3, 12 patients (21 limbs) were included and at T6, 6 patients (13 limbs). CDT comprised a variety of interventions (Figure 2 ).

Figure 1:

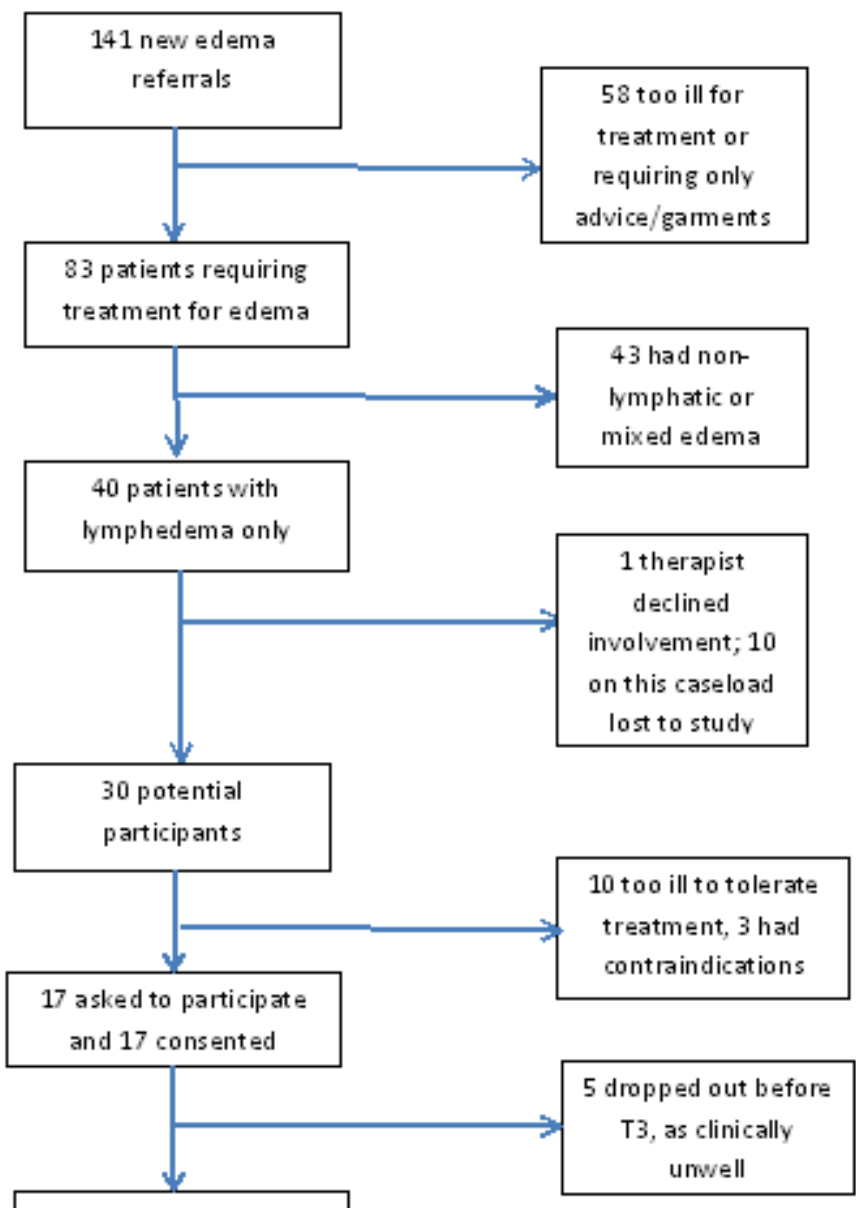

12 patients in study 
Table 2: Participants in Study

\begin{tabular}{|c|c|c|c|c|c|c|c|c|}
\hline Patient & gender & Age & Diagnosis & $\begin{array}{l}\text { Site of } \\
\text { swelling }\end{array}$ & $\begin{array}{l}\text { Edema } \\
\text { onset } \\
\text { (self } \\
\text { report) }\end{array}$ & $\begin{array}{l}\text { Re-assessed } \\
\text { at time- } \\
\text { points }\end{array}$ & $\begin{array}{l}\text { Treatment } \\
\text { duration } \\
\text { (days) }\end{array}$ & $\begin{array}{l}\text { Survival } \\
\text { from last } \\
\text { treatment } \\
\text { (days) }\end{array}$ \\
\hline 1 & $\mathrm{~F}$ & 59 & ovarian & $1 \mathrm{leg}$ & Few weeks & T3 & 15 & 26 \\
\hline 2 & $M$ & 45 & Iymphoma & $1 \mathrm{leg}$ & 2 weeks & T3 & 17 & 4 \\
\hline 3 & $\mathrm{~F}$ & 61 & pancreatic & 2 legs & months & T3, T6 & 14 & 102 \\
\hline 4 & $F$ & 71 & pancreatic & 2 legs & 2 weeks & T3 & 7 & 3 \\
\hline 5 & $\mathrm{~F}$ & 72 & pancreatic & 2 legs & 2 weeks & T3 & 42 & 14 \\
\hline 6 & $M$ & 74 & prostate & 2 legs & 3 weeks & T3 & 39 & 62 \\
\hline 7 & $\mathrm{~F}$ & 42 & breast & 2 legs & 4 weeks & T3, T6 & 23 & 240 \\
\hline 8 & $\mathrm{~F}$ & 54 & breast & 2 arms & 2 weeks & T3, T6 & 11 & 55 \\
\hline 9 & $\mathrm{~F}$ & 69 & breast & 2 legs & months & T3, T6 & 9 & 262 \\
\hline 10 & $\mathrm{~F}$ & 73 & vaginal & 2 legs & 3 weeks & T3,T6 & 11 & 9 \\
\hline 11 & $\mathrm{~F}$ & 70 & ovarian & 2 legs & 2 weeks & T3 & 39 & 10 \\
\hline 12 & $\mathrm{~F}$ & 78 & breast & $1 \mathrm{leg}$ & 4 weeks & T3, T6 & 53 & 204 \\
\hline
\end{tabular}

\section{Treatments Used}

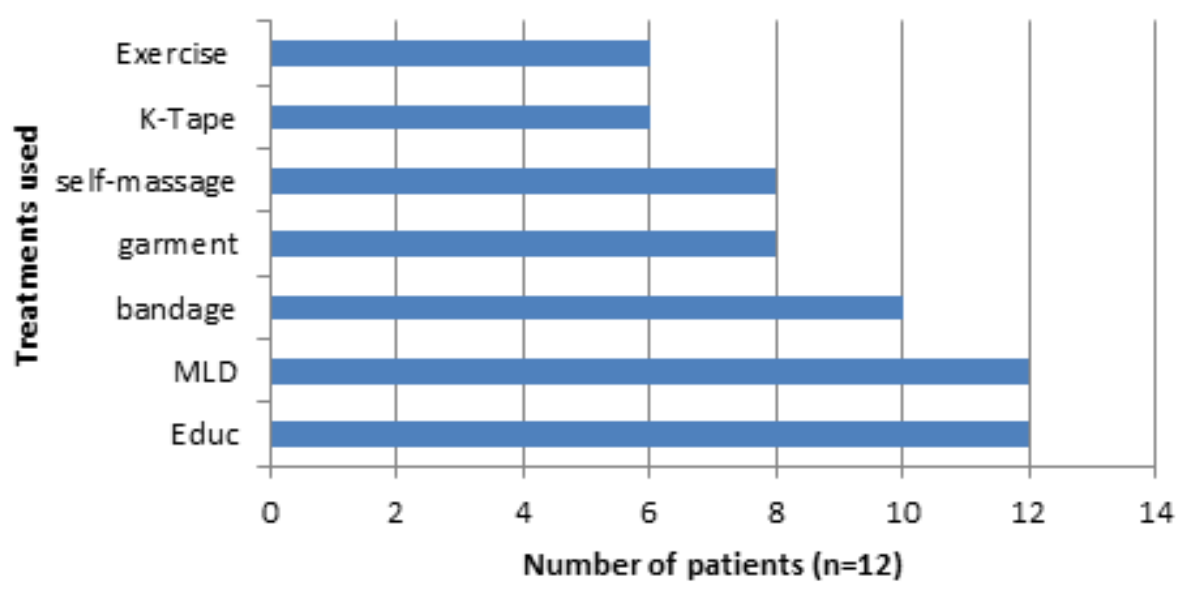

Figure 2: 


\section{Volume reduction:}

At T3: $16 / 21$ limbs reduced in volume, median reduction was $443 \mathrm{mls}$ ( $5.3 \%$ volume). Wilcoxin Signed Ranks Test showed significant change $[Z=-2.5, p=0.01, r=0.5]$. At T6, 11/13 limbs reduced in size, median reduction was $658 \mathrm{mls}(9 \%)$, which was significant $(Z=-2.4, p=0.013, r=0.66]$. See Table 3. There was no correlation between volume reduction and survival at $T 3$, but a strong correlation at T6 (Pearson's correlation coefficient $r=-0.7, p=.001$ ).

\section{Skin Changes}

Post- CDT, abnormal skin colour did not change (Figure 3). Skin thickness reduced significantly at T3 (Wilcoxin Signed Rank Test $Z=-3.354, p=0.001, r=0.73)$ and at T6 $(Z=-3.247, p=0.001, r=0.9)$. Surface abnormalities reduced significantly at $\mathrm{T} 3(\mathrm{Z}=-2.71, \mathrm{p}=0.007, \mathrm{r}=0.6)$ and $\mathrm{T} 6(\mathrm{Z}=-2.55, \mathrm{p}=0.011, \mathrm{r}=0.71)$. Changes occurred with and without volume reduction. No correlation was found using Pearson's product between skin improvement and extent of volume reduction at T3 or T6.

\section{Figure 3: Skin Changes with treatment}
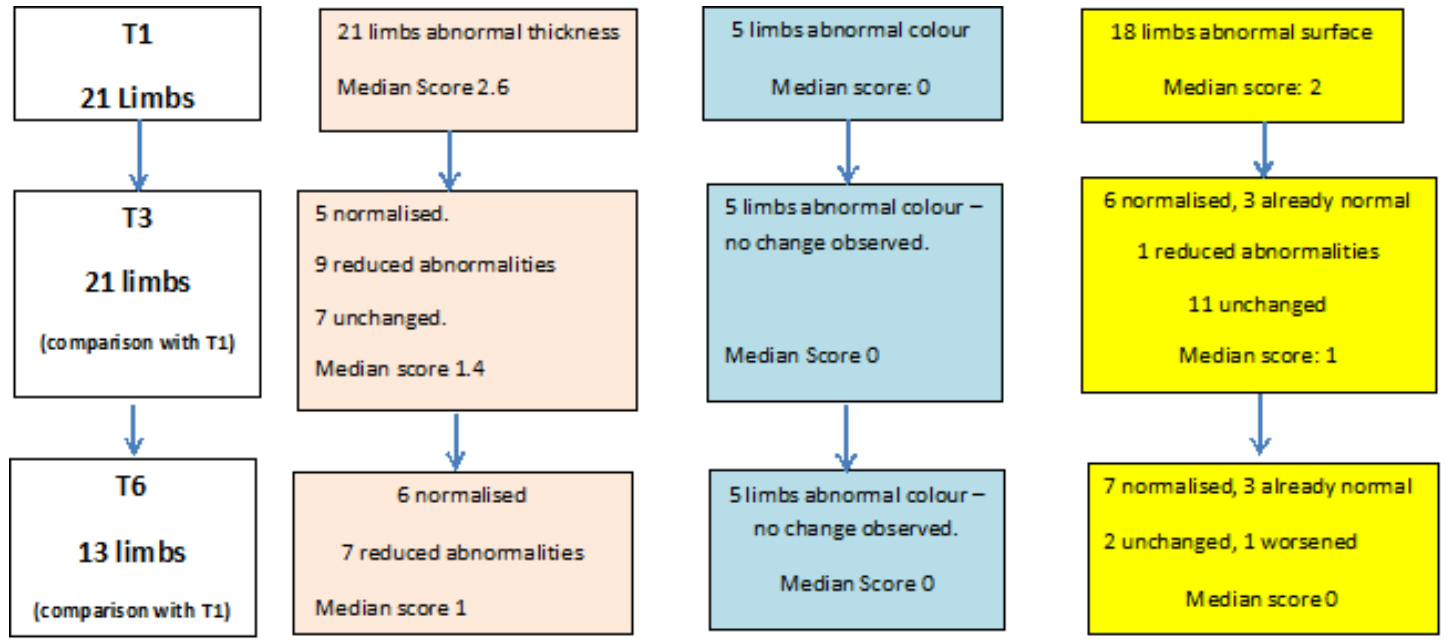

Note: 1 point $=1 / 4$ limb surface

Quality of life:

9/12 subjects were asked about changes post-CDT. At T3, all nine reported positive changes, one of whom had worsening edema.

The most common theme was symptom improvement. Patients reported reductions in pain/ tightness, more comfort, feeling looser, lighter, and skin was softer.

"My tummy feels lighter. It's easier to breathe"

The patient with worsening edema also reported reduced pain and tightness. 
The second most common theme was functional improvement. It was easier to move, walk, and to do specific tasks.

"I can use my mobile phone again"

Lastly, changes to bodily appearance were reported. Limbs were smaller, bony areas emerged, and a sense of normalcy returned. It was easier to apply clothing/shoes.

"It looks like a lady's leg again".

At T6, 5/6 remaining patients were questioned about reported changes. The above themes were reiterated, however one subject, with worsening lymphedema, noticed that applying clothing was harder.

\section{Discussion:}

The benefits of CDT for lymphedema are well-established in cancer survivors, but not in PC patients. This study, the first known, observed the effects of individually-tailored CDT in a convenience sample of 12 PC cancer patients with limited survival.

In general, CDT was well-tolerated, being discontinued once the burden outweighed the benefits. There was attrition of 5 patients before T3, and five before T6. There was predominance of lower limb lymphedema (21 legs, 2 arms), concurring with two previous studies [19, 20].

\section{Limb Volume:}

At both time-points, there was statistically significant median reduction in volume. Extent of volume reduction was not linked to survival at T3 but at T6, those with larger reductions had longer survival times. Results suggest that patients with limited survival can achieve volume reduction with $\mathrm{CDT}$, and that some may benefit more than others.

Skin Quality:

The biggest issue in recording changes to skin quality, was lack of a suitable measurement tool, as reported previously [13]. Our tool, while not yet validated, showed improvements in texture and surface of skin, but not colour (Figure 3). Improvements did not correlate with volume reduction and even occurred with increases. This suggests that CDT may be worthwhile in PC patients for improving skin integrity, even without expected volume change.

Lymphoedema-specific QOL

Improving QOL is a major goal of treating lymphedema in PC patients [13]. Measurement remains a challenge, as existing lymphedema-specific tools proved unsuitable. Our qualitative questions, introduced ad hoc, had no research to guide them. In particular, our questions did not allow for emotional responses to treatment, treatment burden or for broader themes to emerge. However, valuable information was elicited: CDT reduced discomfort, improved function and limb aesthetics, and there was a return towards normalcy. 
These findings prompt the development of a lymphedema-specific QOL tool for PC patients. Qualitative research is needed on the experience of CDT in PC patients to guide this.

\section{Limitations and Suggestions:}

Our pilot study has a number of limitations, which should be addressed by future studies. Clinical tools to measure both skin integrity and lymphoedema -specific QOL need to be developed, while keeping patient burden to a minimum.

We used a convenience sample of patients, and sample size was small. Larger studies would allow for more rigorous statistical analysis of effectiveness. The treating physiotherapists both recruited and recorded results, therefore gatekeeping and bias towards reporting good effects were possibilities. Independent recruitment and blinding of researchers are obvious requirements for future studies.

This study was pragmatic, with varying treatment regimes and time frames, which could be standardised in future trials. It would be beneficial to note albumin levels and physical function at initial time-point to determine if these affect volume reduction or predict completion of programme.

Despite these limitations, results suggest that advanced cancer patients with limited survival may obtain multiple benefits from CDT.

\section{Conclusion:}

Lymphedema management of PC patients using CDT has no research to prove its effectiveness, despite widespread clinical use. This prospective pilot study, the first known, evaluates the effects of CDT on lymphedema in patients with advanced cancer and with poor survival. The biggest obstacle was lack of valid tools to evaluate changes in lymphedema-specific QOL and skin quality. Volume reductions occurred in this population and skin quality improved. QOL improvements included increased function, symptom reduction and normalisation of limb aesthetics. Further research is warranted.

\section{Acknowledgements:}

There were no conflicts of interest.

Thank you to our physiotherapy colleagues, who assisted with data collection. Many Thanks to Dr. Jean Saunders (University of Limerick) for statistical advice and to Dr. Judy Pettigrew (University of Limerick) for her advice on qualitative analysis.

\section{References:}

1. Williams, A., Franks, P and Moffat, C. (2005) 'Lymphoedema: estimating the size of the problem', Palliative Medicine, 19: 300-313

2. ILF \& CLF, International Lymphoedema Framework and Canadian Lymphedema Framework (2010)' The management of lymphoedema in advanced cancer and oedema at the end of life', online available: http://www.soffed.co.uk/lymphorg/wp-content/uploads/2016/03/Palliative-

Document.pdf [accessed 5 march 2017]

3. Frid, M., Strang, P., Friedrichsen, M. and Johansson, K. (2006) 'Lower limb Lymphedema:

Experience and perceptions of cancer in the late palliative stage, Journal of Palliative Care', 22(1): 5- 
4. Shrubb, D and Mason, $W(2006)$ 'The management of deep vein thrombosis in lymphoedema: a review' British Journal Community Nursing' 11(7): 292-7.

5. Honnor (2009) 'Understanding the management of lymphoedema for patients with advanced disease', International Journal of Palliative Nursing, 15(4): 162-69.

6. Flour, M. (2013) 'Dermatological Issues in lymphoedema and chronic oedema', Journal of Community Nursing, 27(2): 27-32.

\section{Finnane, A., Minika, J.and Hayes, S. (2015) 'Review of the evidence of lymphedema treatment} effect', American Journal of Physical Medicine and Rehabilitation, 94(6): 483-498

8. Williams, A. (2004) 'Understanding and managing lymphoedema in people with advanced cancer', Journal of Community Nursing, 18(11): 30-40

9. Todd, M (2009) 'Understanding lymphoedema in advanced disease in a palliative care setting', Int J Palliative Nursing, 15(10): 474-480

10. Cooper, G (2012) 'Lymphoedema treatment in palliative care: a case study', British Journal of Nursing, 21(15): 897-903

11. Beck, M., Wanchai, A., Stewart, B., Cormier, J. and Armer, J. (2012) 'Palliative care for cancerrelated lymphedema: A systematic Review', Journal of Palliative Medicine, 15(7): 821-8.

12. Clemens, K., Jaspers, B., Klaschick, E and Nieland, P. (2010) 'Evaluation of the clinical effectiveness of physiotherapeutic management of lymphoedema in palliative care patients', Japanese Journal of Clinical Oncology, 40(10): 1068-1072

13. Cobbe, S., real S, and Slattery S. (2017) 'Assessment, treatment goals and interventions for oedema/lymphoedema in palliative care' International Journal of Palliative Nursing, 23(3): 111-119.

14. Oremus, M., Walker, K., Dayes, I. and Rania, P. (2010) Diagnosis and treatment of Secondary Lymphedema. Agency for healthcare research and Quality Evidence: Maryland. 2010 Available online: https://www.cms.gov/Medicare/Coverage/DeterminationProcess/downloads/id66aTA.pdf [accessed sept 27 2016]

15. NLN, National Lymphedema Network( 2011) NLN Position Statement: The Diagnosis and treatment of Lymphedema. Online available:

http://www.lymphnet.org/pdfDocs/position.papers/Diagnosis.Treatment.pdf

[accessed sept 27 2016]

16.Casley-Smith J (1994) 'Measuring and presenting peripheral oedema and its alterations' Lymphology, 27: 57-70

17. Keeley, V., Crooks, S., Locke, J., Veigas, D., Riches, K and Hilliam, R. (2010) 'A quality of life measure for limb lymphoedema', Journal of Lymphoedema, 5(1): 26-37

18. Braun V. and Clarke V. (2006) 'Using thematic analysis in psychology', Qualitative research in Psychology, 3:77-101 
19.Real, S., Cobbe, S., Slattery, S. (2016) 'Palliative Care Edema: Patient Population, Causal Factors, and Types of Edema Referred to a Specialist Palliative Care Edema Service '. J Palliat Med. 2016 Jul;19(7):771-7

20.Thompson, $\mathrm{M}$ and Walker, J. (2011)' Collaborative lymphoedema management: developing a clinical protocol', Int J Pall Nurs, 17(5): 231-8.

\section{Appendix 1: Skin Assessment Tool}

\begin{tabular}{|l|l|l|l|}
\hline Skin Condition & T3 & T6 \\
$\begin{array}{l}\text { (1)1-25\%, (2) 25-49\%, (3) 50- } \\
\text { Record Abnormalities ONLY }\end{array}$ & & & \\
\hline $\begin{array}{l}\text { Colour: normal, red, pink, } \\
\text { brown }\end{array}$ & & & \\
\% & & & \\
\hline $\begin{array}{l}\text { Thickness: normal, thin, pitting } \\
\text { oedema, non-pitting (hard) \% }\end{array}$ & & & \\
\hline $\begin{array}{l}\text { Surface: normal, dry, shiny, } \\
\text { hyperkeratosis, lymphoceles, } \\
\text { papillomatosis, lymphorrhoea \% }\end{array}$ & & & \\
\hline
\end{tabular}


Table 3: Volume changes at T3 and T6

\begin{tabular}{|c|c|c|c|c|c|c|c|}
\hline Patient & $\begin{array}{r}\text { Limb } \\
\text { Volume } \\
\mathrm{T} 1 \text { (mls) }\end{array}$ & $\begin{array}{r}\text { Limb volume } \\
\text { T3 }\end{array}$ & $\begin{array}{r}\text { Difference } \\
\text { T1 to T3 } \\
\text { (mls) }\end{array}$ & $\begin{array}{l}\% \text { change } \\
\text { at T3 }\end{array}$ & $\begin{array}{l}\text { Volume } \\
\text { T6 }\end{array}$ & $\begin{array}{l}\text { Difference } \\
\text { T1 to T6 } \\
\text { (mls) }\end{array}$ & $\begin{array}{l}\text { \% change at } \\
\text { T6 }\end{array}$ \\
\hline P1 & 9383 & 9358 & -25 & -0.2 & - & - & - \\
\hline P2 & 8929 & 6969 & -1960 & -22 & - & - & - \\
\hline \multirow[t]{2}{*}{ P3 } & 7075 & 6605 & -443 & -6.3 & 6362 & -685 & -9.7 \\
\hline & 6446 & 6254 & -192 & -0.3 & 6147 & -299 & -4.6 \\
\hline \multirow[t]{2}{*}{ P4 } & 7469 & 7664 & +195 & +2.6 & - & - & - \\
\hline & 7880 & 6734 & -1146 & -14.5 & - & - & - \\
\hline \multirow[t]{2}{*}{ P5 } & 7973 & 8373 & +400 & +5.1 & - & - & - \\
\hline & 7656 & 8373 & +717 & +9.4 & - & - & - \\
\hline \multirow[t]{2}{*}{ P6 } & 10012 & 9542 & -470 & -4.7 & 9407 & -601 & -6.4 \\
\hline & 10009 & 8944 & -1065 & -10.6 & 9883 & -126 & -1.2 \\
\hline \multirow[t]{2}{*}{ P7 } & 8701 & 8781 & +81 & +0.1 & 6771 & -1929 & -22.2 \\
\hline & 8037 & 8722 & +686 & +8.5 & 6519 & -1518 & -18.9 \\
\hline \multirow[t]{2}{*}{ P8 } & 3820 & 3687 & -133 & -3.5 & 3162 & -658 & -17.2 \\
\hline & 3908 & 3484 & -424 & $\begin{array}{l}-10.9 \\
\end{array}$ & 2852 & -1056 & -27 \\
\hline \multirow[t]{2}{*}{ P9 } & 8838 & 8365 & -472 & -5.3 & 7821 & -1017 & -1.2 \\
\hline & 8873 & 8295 & -578 & -6.5 & 7754 & -1118 & -12.6 \\
\hline \multirow[t]{2}{*}{ P10 } & 7621 & 7421 & -200 & -2.6 & 8349 & +729 & +9.6 \\
\hline & 8400 & 7114 & -1286 & -15.3 & 8785 & +39 & +4.6 \\
\hline \multirow[t]{2}{*}{ P11 } & 6471 & 5536 & -935 & -14.4 & - & - & - \\
\hline & 6455 & 5355 & -1100 & -17 & - & - & - \\
\hline P12 & 8000 & 6230 & -1770 & -22 & 6848 & -1152 & -14 \\
\hline Median & 7973 & 7421 & -443 & -5.3 & 6848 & -658 & -9 \\
\hline IQRange & 2083 & 2305 & 1111 & 14.4 & 2316 & 982 & 17 \\
\hline
\end{tabular}

Note: negative values show reduction in volume 